Running head: Ideological microaggressions

\title{
Perceptions of microaggressive behavior across the ideological spectrum
}

\author{
Craig A. Harper* \\ Nottingham Trent University (UK)
}

Correspondence should be addressed to:

Dr. Craig Harper

Department of Psychology (Chaucer 4104), Nottingham Trent University

50 Shakespeare Street, Nottingham, NG1 4BU, UK

Email: craigaharper19@gmail.com. Tel.: +44 (0)115 8484718.

\section{Funding Note}

This work was possible thanks to a contribution from the Nottingham Trent University QR Fund.

\section{Acknowledgements}

Thanks go to Dr. Ian Elliott, Prof. Linda Skitka, and Dr. Harry Purser for helpful comments on an earlier draft of this work. 


\begin{abstract}
Microaggressions - subtle slights that communicate implicit bias - have become a widespread concern in recent years. However, the empirical credibility of microaggression theory has been questioned due to a lack of conceptual clarity and the prevalence of methodological biases within microaggression research. Challenging the empirical validity of the traditional demographics-based microaggression concept, this study examined the potential for crossspectrum microaggression perception being a method for derogating opposition viewpoints, consistent with existing work on ideological prejudice. Using an experimental online survey $(N=404)$, there was a significant association between participants' ideological orientation and their judgements of the 'perpetrators' and 'victims' of microaggressions when 'victims' were associated with leftist causes, but not right-wing causes. These associations were not moderated by emotional investment in ideological orientation (i.e., collective narcissism). Implications for microaggression theory, diversity training programs, and the study of politically-salient individual differences are subsequently discussed.
\end{abstract}

Keywords: microaggressions; political ideology; collective narcissism; implicit bias; ideological prejudice 


\section{Perceptions of microaggressive behavior across the ideological spectrum}

There is a growing awareness of the emerging problem of so-called 'microaggressions'. These are broadly defined as "everyday verbal, nonverbal, and environmental slights, snubs, or insults, whether intentional or unintentional, that communicate hostile, derogatory, or negative messages to target persons based solely upon their marginalized group membership" (Sue, 2010, p. 24). They are usually contextual ambiguous with regards to the underlying motivations or reasoning of the alleged perpetrator (e.g., a White professor suggesting to a student of Asian descent that they are impressed by their use of English in academic writing, or somebody suggesting that "the best person should be given the job" in discussions about affirmative action). According to those affiliated with and allied to the microaggression theory (MAT), this ambiguity makes microaggressions and their effects even more malicious, as they leave the receiver uncertain as to whether they have actually been victimized (Sue, Capodilupo, \& Holder, 2008).

\section{A review of the microaggression theory}

Recent reviews of the MAT by Elliott (2016) and Lilienfeld (2017) suggest that the theory contains several important theoretical shortcomings. Specifically, these critics identify four specific limitations. First, the theory is internally incoherent, as it assumes cognitive vulnerabilities in some individuals but not others. That is, Sue (2010) implies that 'majority' group members microaggress against 'minority' group members due to the formers' reliance on implicit (vs. deliberative) cognition. This argument seems flawed as it assumes psychological deficits (i.e., the inability to overcome 'implicit biases') among some (majority group members) but not others (minority group members). This, ironically, could be a prejudicial claim in itself. Further, this approach dichotomizes individuals into so-called 'majority' and 'minority' groups, and fails to recognize the intersectional identities (e.g., an 
individual may be male (majority), Black (minority), cisgendered (majority), and homosexual (minority) simultaneously) that are inherent to the ideological worldview typically held by those who adhere to the MAT.

Second, MAT is operationally vague to such an extent to be unfalsifiable, as any statement is potentially a microaggression based on perceptions of perpetrators' intent. This is linked to the first criticism in that a range of statements or actions could be (mis)construed as being microaggressive in nature. One of the most-publicized list of microaggressions was published by the University of California - Santa Cruz (2015) who, citing Sue's (2010) operationalization of microaggressions, produced a document entitled 'Recognizing Microaggressions and the Messages They Send'. Examples of such microaggressions listed in this document are presented in Table 1. As can be seen in this list, core aspects of contemporary Western culture (e.g., the expressed belief in meritocratic hiring processes, and explicitly rejecting different treatment based on racial or gender demographics) can be labelled as microaggressions under some circumstances.

Third, much of the available microaggression research is methodologically problematic. For example, the purposive sampling of minority groups (e.g., Sue, Bucceri, Lin, Nadal, \& Torino, 2010; Watkins, LaBierre, \& Appio, 2010), and the use of leading questions to elicit specific examples of alleged microaggressions (e.g., "An employer or co-worker treated me differently than White co-workers"; Nadal, 2011) embed of particular political value markers into the theory itself. That is, by framing microaggression perception items in terms of strict dichotomies related to identity politics, researchers prime these perceived imbalances in their participants. Similarly, the lack of representation of 'majority' group members ignores that fact that these individuals may too face everyday slights and low-level discrimination in contemporary society. The clearest example of this in the current context is the growing unrest on college and university campuses, with conservative speakers being de-platformed 
(i.e., invited to speak on campuses, before having their invitations revoked as a result of activism prior to the event) at a rate higher than ever before (Stevens, 2017), and professors using the so-called "progressive stack" (Picower, 2013) to ask for class contributions from students with historically under-represented demographic characteristics).

Table 1. Examples of microaggressions and their subtle implicit messages (adapted from University of California - Santa Cruz, 2010)

\begin{tabular}{|c|c|c|}
\hline Type of microaggression & Example & Communicated message \\
\hline \multirow[t]{2}{*}{ Alien in one's own land } & $\begin{array}{l}\text { "You speak English very } \\
\text { well" }\end{array}$ & You are not a true American \\
\hline & $\begin{array}{l}\text { A person asking an Asian } \\
\text { American or Latino American } \\
\text { to teach them words in their } \\
\text { native language }\end{array}$ & $\begin{array}{l}\text { Your ethnic or racial identity } \\
\text { makes you exotic or } \\
\text { different }\end{array}$ \\
\hline Color blindness & $\begin{array}{l}\text { "America is a melting pot" } \\
\text { "When I look at you, I don't } \\
\text { see color" }\end{array}$ & $\begin{array}{l}\text { You should just assimilate } \\
\text { Denial of the individual as a } \\
\text { racial or cultural being }\end{array}$ \\
\hline Myth of meritocracy & $\begin{array}{l}\text { "I believe that the most } \\
\text { qualified person should get the } \\
\text { job" } \\
\text { "America is the land of } \\
\text { opportunity" }\end{array}$ & $\begin{array}{l}\text { Minority groups are given } \\
\text { unfair benefits because of } \\
\text { their position in society } \\
\text { People of color are too lazy } \\
\text { and/or incompetent, and just } \\
\text { need to work harder }\end{array}$ \\
\hline Second-class citizen & $\begin{array}{l}\text { A female doctor being } \\
\text { mistaken for a nurse } \\
\text { Raising your voice or } \\
\text { speaking slowly when } \\
\text { addressing a blind student }\end{array}$ & $\begin{array}{l}\text { Women should occupy } \\
\text { nurturing positions } \\
\text { People with disabilities are } \\
\text { lesser in all aspects of } \\
\text { mental and physical } \\
\text { functioning }\end{array}$ \\
\hline
\end{tabular}

Fourth, the very framing of the MAT calls into question its practical utility in addressing prejudice and discrimination. That is, if microaggressions are rooted in the implicit malevolence of the 'perpetrator', explicitly educating such individuals to transcend their implicit biases (a skill that MAT adherents imply that they do not possess) may not yield the wanted returns (see Lai et al. (2016) for a review of the effectiveness of implicit bias 
training methods). If this is the case, then the MAT is diagnosing a problem to which there is no solution.

These criticisms call into question the very conceptual foundations of the MAT. That is, if microaggressions are not accurately definable or quantifiable, this label acts more as a meme that can be used for labeling individual perceptions of outgroup malevolence than it is a meaningful diagnostic label for actual malevolent behaviors. With this in mind, it may be necessary to study microaggressions from the perspective of the receiver (or, perhaps more accurately, the perceiver). That is, if microaggressions cannot be objectively defined, and any number of utterances could be interpreted as microaggressions (see Table 1), pertinent research questions may investigate the psychological traits, dispositions, and contexts under which people perceive themselves as being victims of others' subtle implicit biases. This point was made by Lilienfeld (2017), who argued that the prime candidates for examining the psychological or motivated bases of microaggression perception include negative emotionality (Watson \& Clark, 1984) and 'Big Five' personality traits (Costa \& McRae, 1992; DeYoung, Quilty, \& Peterson, 2007; Goldberg, 1993). In the present study, microaggression perception was studied within the context of ideological motivated cognition, owing to the lack of research currently available on political microaggressions, the ongoing social debate surrounding political polarization, and the aforementioned political values that may be inherent the MAT.

\section{Microaggression perception as politically-symmetric motivated social cognition}

With Sue's (2010) classical conceptualization of microaggressions being framed as powerbased interactions between majority and minority group members, sensitivity to perceiving them may be most common on the political left (Campbell \& Manning, 2018; Friedersdorf, 2015). This is because those with a left-wing orientation place a greater moral importance on 
protecting ostensibly disadvantaged groups from harm (Haidt, 2012), and thus may be more sensitive to power differentials within wider society. However, motivated social cognition is not limited to left-wing groups, and may be exaggerated among those at both extremities of the political spectrum (e.g., Crawford, 2014; Jost \& Amodio, 2012; Skitka, Hanson, \& Wisneski, 2017). While a comprehensive review of the personality constructs associated with motivated cognition is beyond the scope of this article, one concept of particular interest to microaggression perception may be collective narcissism.

Collective narcissism (Golec de Zavala, Cichocka, Eidelson, \& Jayawickreme, 2009) is an individual difference construct characterized by exaggerated feelings of moral superiority, ingroup pride, and outgroup derogation (Golec de Zavala, Cichocka, \& Bilewicz, 2013). It has been suggested that suggests that collective narcissism may represent a form of defense against psychological vulnerabilities or low self-esteem (e.g., Murteira, Golec de Zavala, \& Waldzus, 2017). In line with Branscombe and Wann's (1994) work, it may be expected that those with a deep investment in their ideological position (i.e., higher rates of collective narcissism) would derogate ostensibly (micro)aggressive outgroup members when an ingroup member of community identity is criticized. According to Cichocka (2016), collective narcissism is associated with seeking external gratification for one's ingroup, and further is associated with a sensitivity to perceived threats to that group identity. Similarly, Golec de Zavala, Peker, Guerra, and Baran (2016) reported a series of studies in which collective narcissism predicted a sensitivity to ingroup insult (e.g., derogatory movies and jokes being made about one's country). Further, collective narcissists were more likely to act in a retaliatory manner to the sources of these alleged insults than were non-narcissists. While these insults are more overt and explicit than alleged microaggressions, these findings do support the idea that collective narcissism may moderate perceptions of microaggressive behaviors, with collective narcissists being more sensitive to perceived ingroup slights. 
There is little reason to believe that those on the political right (who have been the most-implicated group in relation to collective narcissism) should respond to microaggressions any differently to those on the political left when the alleged aggression is directed towards an ideologically-salient victim group. A range of recent literature has demonstrated how those on the left and right of the political spectrum appear to respond to outgroup-based stimuli in a symmetric manner. For example, individuals of both sides have a similar tendency to avoid each other's arguments (Frimer, Skitka, \& Motyl, 2017), express prejudice against ideologically-dissimilar others (Crawford, Kay, \& Duke, 2015), exaggerate ideological differences (Graham, Nosek, \& Haidt, 2012), deny ideologically-inconsistent scientific conclusions (Washburn \& Skitka, 2017), and sacralize ideologically-salient topics (Frimer, Tell, \& Motyl, 2016).

These findings contradict a host of established social psychological research findings, though. That is, researchers have consistently reported differences in the personality profiles (Carney, Jost, Gosling, \& Potter, 2008), cognitive styles (Talhelm et al., 2015), endorsement of moral values (Haidt, 2012), and the expression of a host of prejudicial views (Hodson \& Dhont, 2015) between self-identified liberals and conservatives (for a review of this work on ideological asymmetries, see Jost, 2017). While these liberal-conservative differences are well established within the social and political psychological literature, they may reflect intuitive ideological biases within the field itself, both on the part of its scholars and in relation to the methodologies used to obtain such results (Brandt \& Spälti, 2018; Reyna, 2018). Thus, a more ecological approach may be needed to effectively examine the hypothesized symmetry of political behavior (Kessler, Proch, \& Elad-Strenger, 2017), with ideological differences being eliminated when partisans are provided with ideologicallysalient research stimuli. This approach was adopted in the present study. 


\section{The present study}

To date, little-to-no attention has been paid as to whether innocuous slights against groups associated with the right-wing are interpreted by those on the political right as being driven by malicious intent in a manner that would be consistent with a cross-spectrum application of the MAT. Further, microaggression perception has not been studied in relation to perceivers' ideological perspective, rather than their demographic characteristics. The present study adopted an experimental survey designed to bring together empirical work on motivated social cognition and microaggression perception. Specifically, this work sought to examine the question as to whether those on the political left and right may similarly express punitive judgements of those engaging in ostensible microaggressions against individuals or groups that are traditionally more aligned with their 'side'.

Hypothesis 1 predicted that liberals would judge the perpetrators of 'left-wing microaggressions' (slights against women, ethnic minorities, and liberals) more punitively than conservatives. The opposite trend was predicted for judgments of the perpetrators of 'right-wing microaggressions' (slights against men, Whites, and conservatives). These targets were chosen for inclusion as they represent key groups in long-standing and ongoing social debates about inequality and inequity (Campbell \& Manning, 2018; Pinker, 2002). Hypothesis 2 predicted that these effects would be moderated by collective narcissism. That is, as an individual became more morally- and emotionally-invested in their ideological position, the greater their condemnation of slights against groups associated with their political 'side' would be. 


\section{Methods}

\section{Participants}

Using the G*Power algorithm (Faul, Erdfelder, Buchner, \& Lang, 2009), a minimum sample of 146 was required to detect a medium effect size (partial $\eta^{2}=0.06$, consistent with recent findings in relation to politically-motivated social cognition; Frimer et al., 2017) with 95\% power. In order to account for potential withdrawal, and to secure a large number of participants from across the ideological spectrum, a target of 400 participants was set. A total of 404 Americans $\left(60 \%\right.$ female; $M_{\text {age }}=41.25$ years, $\left.S D=13.27\right)$ were recruited using Amazon's Mechanical Turk (MTurk) crowdsourcing system. Owing to the set-up of the survey, there were no incomplete datasets, and nobody withdraw from the study. Before any data were analyzed, responses were checked for signs of 'speeding' (operationalized as a total survey completion time that was less than one-third of the median completion time). No participants violated this cut-off point, meaning that data from all participants were included in all analyses reported in this paper. Participants signed up to the task on MTurk through their online accounts. The survey was advertised as being one that sought to examine the impact of political version on social judgments. All participants were informed about the tasks that they would be asked to complete (i.e., reading about an interaction between groups, and providing some judgements about this interaction), but were naïve to the specific hypotheses of the study. The median completion time for the study was 4.48 minutes, and all participants were reimbursed US $\$ 0.75$.

\section{Measures}

Demographics. At the beginning of the survey, participants were asked to provide information about their gender (male/female), age (in years), and ideological orientation (rated on a nine-point scale: 'completely liberal', 'mostly liberal', 'quite liberal', 'slightly 
left-leaning', 'centrist', 'slightly right-leaning', 'quite conservative', 'mostly conservative', or 'completely conservative'). These questions were answered first in order to allow for suitable allocation to experimental conditions later in the survey, ensuring a more equal proportion of 'liberals' (those scoring 1-3; $n=166$ ), 'moderates' (those scoring 4-6; $n=81$ ), and 'conservatives' (those scoring 7-9; $n=157$ ) to be allocated to each experimental vignette (see below). That is, separate survey 'branches' were set up in order to more systematically randomize allocation to each vignette within each of the three ideological groupings, rather than randomization occurring between all participants across the sample. This ensured that both left-wing microaggressions and right-wing microaggressions were distributed equally across the ideological spectrum.

Collective Narcissism Scale. The nine-item collective narcissism scale (Golec de Zavala et al., 2009) was used to examine the motivated investment in, and perceived superiority of, participants' political viewpoints. In the original iteration of this measure, items are framed in relation to "my group", needing respondents to be separately primed as to what reference group they should consider. In this study, participants were asked to respond statements about the perceived moral righteousness people who shared their political views. Items (e.g., "If people with my political views had a major say in the world, the world would be a much better place”) were responded to using a six-point Likert scale, anchored from 1 (totally disagree) to 6 (totally agree). An average score across the nine items was taken as each individual participant's collective narcissism score. The scale demonstrated very good internal consistency $(\alpha=.85)$. 
Microaggression scenarios. Six microaggression scenarios ${ }^{1}$ were created for the purposes of this study. The 'perpetrator' and 'victim' characteristics of each scenario are presented in Table 2. Taking inspiration from the University of California - Santa Cruz (2015) list of microaggressions, these scenarios were presented as vignettes of approximately 300 words, and described a college professor of political psychology talking about the achievements of different social groups to their students. In each of these scenarios, the professor made a comment that suggested 'cultural influences' could explain racial differences in educational attainment, 'personal choices' could explain gender differences in careers, or a lack of political diversity on campus risks students being unprepared for life after graduation. These topics reflect core ideological differences in relation to racial and gender differences in achievement, and campus culture, in contemporary social discourse (Campbell \& Manning, 2018). Participants were each presented with one scenario, leading to a completely between-subjects design being implemented. The full wording of these scenarios is provided in the appendix to this paper.

Outcome judgements. Five outcome judgement questions were formulated for the purposes of the study. These examined participants' judgements of both the professor (e.g., "The professor in this story is bigoted") and the students involved (e.g., "I believe that the students in this story are being too sensitive"; reverse-coded). By framing questions in this way, it was possible to tap into perceptions of bigotry or prejudice in alleged perpetrators,

\footnotetext{
${ }^{1}$ Sue's (2010) work defines three distinct types of 'microaggression'. The first (microassaults) represent explicit forms of attack, such as name-calling or purposeful avoidance on the basis of the victim's identity. The second (microinsults) represent rudeness or insensitivity to a victim's identity, such as avoiding eye-contact, or demeaning somebody's cultural heritage. The third (microinvalidations) represent actions or statements that supposedly invalidate the experiences or identity of a victim, such as asking somebody of Asian descent where they are from (and thus implying they are not from the host country). Owing to recent critiques of the 'micro' nature of insults and assaults (e.g., Lilienfeld, 2017), the scenarios used in the present study take the form of microinvalidations, as these represent the subtlest (and therefore most 'micro') approach to outgroup/identity derogation. 'Microassaults' are not considered in the present study as they seem to be more akin to overt expressions of prejudice discrimination (i.e., they are not 'micro' in nature).
} 
and over-sensitivity in alleged victims. As such, the core tenets of the MAT were able to be measured without overtly and explicitly priming the concept of "microaggressions". Each question was responded to using a six-point scale anchored from 1 (strongly disagree) to 6 (strongly agree). Averaging participants' responses to these five questions produced a very reliable composite measure of judgements $(\alpha=.89)$.

Table 2. Microaggression scenario characteristics

\begin{tabular}{lccc}
\hline Scenario & $\begin{array}{c}\text { Characteristics of } \\
\text { Professor } \\
\text { (Perpetrator) }\end{array}$ & $\begin{array}{c}\text { Characteristic of } \\
\text { Target Group } \\
\text { (Victims) }\end{array}$ & $\begin{array}{c}\text { Direction of Alleged } \\
\text { Microaggression }\end{array}$ \\
\hline $1^{\mathrm{a}}$ & White & Blacks & Left-wing victim \\
2 & Male & Women & Left-wing victim \\
3 & Conservative & Liberals & Left-wing victim \\
$4^{\mathrm{a}}$ & Asian & Whites & Right-wing victim \\
5 & Female & Men & Right-wing victim \\
6 & Liberal & Conservatives & Right-wing victim \\
\hline
\end{tabular}

a The difference in terms of the 'non-White' reference group was necessary in this manipulation in order to (1) enhance believability and the activation of social stereotypes, and (2) maintain consistency in the context of the scenarios.

\section{Procedure}

Eligible participants on MTurk responded to an invitation to take part in an online survey looking at 'judgements of social interactions'. This description was chosen such as to not prime culturally-available conceptions of what 'microaggressions' are, which may have skewed the interpretation of the experimental scenarios, and participants' self-reported judgements of these interactions.

After clicking on the survey link, participants read a description of the tasks involved in the survey, as well as a statement of their ethical rights (British Psychological Society, 2014). If they happy to proceed, participants were then asked to explicitly affirm their consent to take part in the study. Following this, they provided demographic information, their selfreported ideological orientation, and responded to the collective narcissism measure. 
Randomization to one of the six microaggression scenarios was then conducted by the survey software (Qualtrics) within each of the political groupings ('Liberals', 'Moderates', and 'Conservatives', as operationalized above) in order to ensure an approximately equal spread of vignettes across the ideological spectrum. The button to advance to the next page of the survey (i.e., the outcome judgement questions) was hidden for 60 seconds once the scenario was on the screen, such as to ensure that participants paid attention to the scenario. This timeframe was chosen after consulting average reading times reported by Balota (2016).

After completing the judgement questions, all participants were provided with a comprehensive debrief detailing the objectives of the study, and a unique four-digit code to confirm their completion on MTurk. This procedure was reviewed and approval by an institutional review board before any data were collected.

\section{Results}

\section{Note on preregistration}

The present study design, materials, and analysis strategy were preregistered through the Open Science Framework (http://bit.ly/2IIOFQC) ${ }^{2}$. This registration suggested separate analyses to test Hypothesis 1 (a 2x2 between-subjects ANOVA) and Hypothesis 2 (a moderated regression analysis). However, both informal and formal reviews of earlier iterations of this paper suggested that a more parsimonious presentation of the data would be to conduct all analyses within the same regression model. As such, this analysis is presented in the text below. The preregistered analyses were also conducted, and were consistent with the data presented in the paper below. These preregistered analyses are available for review in the online supplementary materials to this paper.

\footnotetext{
${ }^{2}$ This preregistration outlines two distinct surveys. However, due to the complexity in the argumentation and the lack of flow between the two studies, these projects are being written up as separate papers. The present paper represents Survey 1 in the preregistration linked here.
} 


\section{Data check: Do the groups represent coherent 'political microaggressions'?}

In order to establish whether specific topics elicited different judgements, a 2 (Direction of Microaggression: Left-Wing Victims vs. Right-Wing Victims) x 3 (Microaggression Topic: Race vs. Gender vs. Politics) analysis of variance (ANOVA) was conducted. This analysis uncovered no main effects (Direction: $F(1,398)=0.84, p=.183$; Topic: $F(2,398)=1.78, p$ $=.433)$. The Direction*Topic interaction was also non-significant: $F(2,398)=2.76, p=$ .065). All effect sizes were negligible (partial $\eta^{2}<0.01$ ). These results were as expected, with subsequent analyses collapsing judgements of the alleged microaggressions into 'Right-Wing Victims' and 'Left-Wing Victims' clusters. This result provided statistical support for arguments made earlier that these conceptually represent politically-salient clusters of "victim groups' (see Pinker (2002) for a thorough discussion of these groupings). Descriptive statistics, further broken down by participants' political ideological grouping, are presented in Table 3.

Table 3. Mean judgements of microaggression scenarios

\begin{tabular}{llccc}
\hline & \multicolumn{2}{l}{ Left-Wing Victims } & \multicolumn{2}{c}{ Right-Wing Victims } \\
\cline { 2 - 5 } Microaggression Topic & $\boldsymbol{n}$ & $\boldsymbol{M}(\boldsymbol{S D})$ & $\boldsymbol{n}$ & $\boldsymbol{M}(\boldsymbol{S D})$ \\
\hline Liberals $(\boldsymbol{n}=\mathbf{1 6 6})$ & & & & \\
Race & 27 & $4.10(0.93)$ & 28 & $3.15(0.97)$ \\
Gender & 28 & $4.14(1.08)$ & 27 & $3.31(1.16)$ \\
Politics & 28 & $3.06(1.01)$ & 28 & $3.16(1.15)$ \\
\hline Vignettes combined & $*$ & $3.95(1.03)$ & 83 & $3.21(1.08)$ \\
\hline Moderates $(\boldsymbol{n}=\mathbf{8 1})$ & & & & \\
Race & 14 & $3.00(1.14)$ & 13 & $3.37(1.14)$ \\
Gender & 13 & $3.34(1.09)$ & 13 & $3.43(0.79)$ \\
Politics & 14 & $2.61(1.07)$ & 14 & $3.33(1.08)$ \\
\hline Vignettes combined & 41 & $2.98(1.06)$ & 80 & $3.38(0.99)$ \\
\hline Conservatives $(\boldsymbol{n}=\mathbf{1 5 7})$ & & & & \\
Race & 25 & $2.86(1.13)$ & 26 & $3.17(1.00)$ \\
Gender & 27 & $2.31(0.99)$ & 27 & $3.62(1.10)$ \\
Politics & 25 & $2.42(0.87)$ & 27 & $3.71(1.18)$ \\
\hline Vignettes combined ${ }^{*}$ & 77 & $2.53(1.01)$ & 80 & $3.50(1.10)$ \\
\hline Note. Higher scores indica)
\end{tabular}

Note. Higher scores indicate more punitive judgements of the alleged microaggressor.

$*$ difference between microaggression target groups is significant at $p<.001$ 


\section{Hypothesis testing}

Both hypotheses (see above) were tested within a three-way, using Model 3 of the PROCESS macro for SPSS (Hayes, 2013). In this model, self-reported political ideology was the key predictor variable $(\mathrm{X})$, predicting judgements of alleged microaggressions $(\mathrm{Y})$. The victim group (e.g., left-wing victims vs. right-wing victims) was entered as the primary moderator (M), with collective narcissism entered as an additional moderator variable (W). Model coefficients are presented in Table 4 . In the model, all continuous variables were mean centered, and 'levels' of the variables were created by using the mean and $\pm 1 S D$ of the scale scores in the current sample.

Table 4. Coefficients in the three-way regression model

\begin{tabular}{lccccc}
\hline Predictor & $\boldsymbol{b}$ & $\boldsymbol{S E}(\boldsymbol{b})$ & $\boldsymbol{t}$ & $\boldsymbol{p}$ & $\mathbf{9 5 \%} \mathbf{C I}(\boldsymbol{b})$ \\
\hline Alleged microaggression target & 0.18 & 0.10 & 1.72 & .09 & {$[-.03, .38]$} \\
Ideological orientation & -0.09 & 0.02 & -4.97 & $<.001$ & {$[-.13,-.05]$} \\
Collective narcissism & 0.07 & 0.06 & 1.18 & .24 & {$[-.05, .19]$} \\
Ideology * Target & 0.28 & 0.04 & 7.74 & $<.001$ & {$[.21, .36]$} \\
Ideology * Collective narcissism & 0.03 & 0.02 & 1.45 & .15 & {$[-.01, .07]$} \\
Target * Collective narcissism & -0.11 & 0.12 & -0.96 & .34 & {$[-.35, .12]$} \\
Ideology * Target * Collective & 0.03 & 0.04 & 0.66 & .51 & {$[-.05, .10]$} \\
narcissism & & & & &
\end{tabular}

Note. 'Target' was coded as ' 0 ' (left-wing targets) and ' 1 ' (right-wing targets). Estimates of $b$ were obtained using the default setting of 5,000 bootstrapped resamples (Hayes, 2013).

The overall regression model was statistically significant, and explained $20 \%$ of the variance in microaggression judgements, $R^{2}=.20, F(7,396)=14.98, p<.001$. Examining the coefficients for each level of analysis, political ideology predicted microaggression judgements, with those scoring closer to the liberal end of the ideological orientation scale judging the experimental scenarios as being more microaggressive than those scoring closer to the conservative end of the ideological spectrum. However, there was a significant interaction between the target group of the alleged microaggression and participants' self- 
reported ideological orientation (see Figure 1). Examining the simple slopes in this interaction using Model 1 of the PROCESS macro, ideology significantly predicted microaggression perception when the targets were associated with the political left, $b=-.23$, $t(400)=-9.34, p<.001,95 \%$ CI (b) $[-0.27,-0.18]$. However, ideological orientation was marginally non-significantly related to microaggression perception when the targets were associated with the political right, $b=0.05, t(400)=1.83, p=.068,95 \% \mathrm{CI}(b)[0.01,0.10]$. The trends within this interaction were both in the expected direction (e.g., self-reported ideological liberalism predicted higher microaggression perception when targets were associated with the left). However, with the ideology regression coefficient failing to reach statistical significance in the case of right-wing-affiliated victims, this analysis can be said to provide only partial support for Hypothesis 1 .

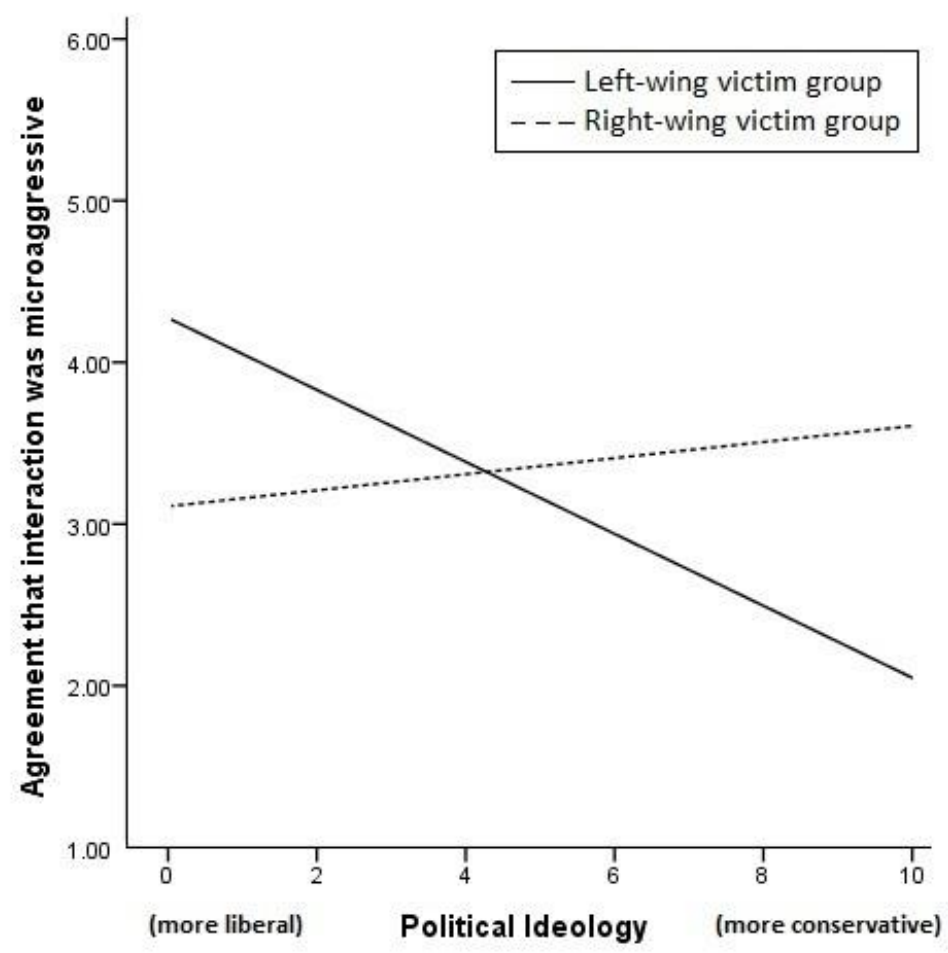

Figure 1. Moderation of the relationship between political ideology and microaggression perception by the target of the alleged microaggression 
There were no other significant interactions in the regression model, including the hypothesized three-way interaction between self-reported ideological orientation, microaggression target, and collective narcissism. That is, the two-way interaction between participants' ideological orientation and the target of alleged microaggressions on microaggression perception was not moderated by ingroup investment. This finding is inconsistent with Hypothesis 2.

\section{Unregistered exploratory analyses}

Sue's (2010) seminal work describes microaggressions as being rooted in implicit prejudices directed towards marginalized individuals on the basis of specific demographic characteristics, such as race, gender, and sexual orientation (as are the three categories specifically mentioned in the subtitle of the 2010 text outlining the concept). Acknowledging this definition, and the challenge posed to it by the present study, an exploratory analysis of the influence of ideological orientation, as compared to these demographic influences, appeared necessary. Of the demographic variables identified by Sue (2010), only information about participants' gender was collected in the present study.

As such, a 2 (Participant Gender: Male vs. Female) x 2 (Ideological Grouping: Liberal vs. Conservative) x 2 (Target: Women vs. Men) between-subjects ANOVA was conducted, with microaggression perception as the dependent variable. As only those who were assigned to one of the gender-based microaggressive scenarios were included in this model, the analyses here are based on a subset of the original sample $(n=212)$. A post-hoc power analysis using observed effect sizes in the ANOVA placed observed power at greater than 99\% (this analysis was run using the G*Power algorithm; Faul et al., 2009). The 'left-wing targets' were females, while the 'right-wing targets' were males. Descriptive statistics for this 
model are presented in Table 5. There were no main effects in the model (all $p \mathrm{~s}>.253$, all partial $\left.\eta^{2} s<.01\right)$.

Table 5. Descriptive statistics examining the relative effects of demographic and ideological influences on perceptions of gender-based microaggressions

\begin{tabular}{|c|c|c|c|c|}
\hline & \multicolumn{4}{|c|}{ Microaggression Targets } \\
\hline & \multicolumn{2}{|c|}{ Females } & \multicolumn{2}{|c|}{$\underline{\text { Males }}$} \\
\hline & $n$ & $M(S D)$ & $n$ & $M(S D)$ \\
\hline \multicolumn{5}{|c|}{ Male participants } \\
\hline Liberals & 8 & $3.80(0.72)$ & 11 & $3.56(1.32)$ \\
\hline Conservatives & 25 & $2.14(0.85)$ & 37 & $3.43(1.01)$ \\
\hline All & 33 & $2.54(1.08)$ & 48 & $3.46(1.17)$ \\
\hline \multicolumn{5}{|c|}{ Female participants } \\
\hline Liberals & 20 & $4.28(1.19)$ & 16 & $3.14(1.05)$ \\
\hline Conservatives & 52 & $2.71(1.04)$ & 43 & $3.57(1.08)$ \\
\hline All & 72 & $3.15(1.29)$ & 59 & $3.46(1.17)$ \\
\hline
\end{tabular}

Note. Figures here are raw means (with standard deviations in parentheses. The statistical findings described in-text are based on estimated marginal means, as calculated within the factorial ANOVA model.

Three interactions were of particular interest. Firstly, if the demographic argument (consistent with Sue, 2010) is to be accepted, there should be a significant interaction between participant gender and the gender of the microaggression targets, with females perceiving higher levels of microaggression in scenarios with female victims (comparative to male victims), and males demonstrating the opposite trend. This interaction was nonsignificant, $F(1,204)=3.60, p=.059$, partial $\eta^{2}=.02$. This finding is inconsistent with the traditional view of the microaggression construct.

Secondly, if the ideological approach advocated the current study is to be accepted, there should be a significant interaction between participant political grouping and the gender of the microaggression targets, with liberals perceiving higher levels of microaggression in scenarios with female victims (comparative to male victims), and conservatives demonstrating the opposite trend. This interaction was significant, $F(1,204)=24.87, p<$ 
.001 , partial $\eta^{2}=0.11$. This interaction was decomposed using tests of simple main effects with Bonferroni-corrected $p$-values. Liberals perceived higher levels of microaggression when the scenarios depicted female victimization, $M_{\text {(difference) }}=0.69, F(1,204)=5.07, p=$ .025 , partial $\eta^{2}=.02,95 \% \mathrm{CI}_{\text {(difference) }}[0.09,1.29]$. In contrast, conservatives perceived higher levels of microaggression when the scenarios depicted female victimization, $M_{\text {(difference) }}=$ $1.07, F(1,204)=36.87, p<.001$, partial $\eta^{2}=.15,95 \% \mathrm{CI}_{\text {(difference) }}[0.73,1.42]$. This finding is consistent with the view that microaggression perceptions may be driven by political ideology.

Thirdly, if an interactionist approach is to be accepted, there should be a three-way interaction between participant gender, participant political grouping, and the gender of microaggression targets. That is, it might be expected that when women are targeted, microaggression perception will be highest among liberal females and lowest among conservative males, with liberal males and conservative females scoring somewhere inbetween. In contrast, it might be expected that when men are targeted, microaggression perception will be highest among conservative males and lowest among liberal females, with conservative females and liberal males between these two groups. In this sense, gender-based concerns would be heightened by ideological orientation. However, this interaction was nonsignificant in the analysis, $F(1,204)=0.44, p=.506$, partial $\eta^{2}<.01$. This is evidence against an interactionist approach to perceptions of gender-based microaggressions.

\section{Discussion}

\section{Overview of key results}

This study examined the idea that perceptions of microaggressions are rooted in ideological investment. In support of Hypothesis 1, a significant interaction was observed between participants' self-reported ideological orientation and the perception that microaggressive 
behavior had taken place. That is, those with a more liberal orientation rated subtle slights against being more microaggressive (operationalized in line with microaggression theory as high levels of perceived bigotry on the part of the 'perpetrator', and lower levels of perceived sensitivity on the part of the 'victims') when victims were groups associated with the political left. In contrast, those with a more conservative ideological orientation saw these interactions as less microaggressive. While not reaching statistical significance $(p=.068)$, the association between ideological orientation trended in the opposite direction when alleged 'victims' were associated with the political right.

These effects were not moderated by collective narcissism, as predicted in Hypothesis 2. There are two possible explanations for this lack of moderating effect. The first is that the result is true, and that ideologically-motivated perceptions of microaggressive motivations are consistent across the ideological spectrum, irrespective of individual participants' levels of emotional and moral investment in their ideology. This result is inconsistent with almost all of the existing literature on collective narcvissism, which suggests that the construct is intricately linked, causally, with an increased sensitivity to ingroup threat and insult (Cichocka, 2016). An alternative interpretation of this lack of moderating effect could be rooted in the measure of collective narcissism itself. The current literature on collective narcissism frames it as a right-wing construct rooted in national or ethnic identity (e.g., Golec de Zavala et al., 2009, 2013; Golec de Zavala \& Cichocka, 2012). This work has also found it to be associated with the social dominance orientation, which is typically observed as an individual difference construct associated with the political right (Ho et al., 2015). This may be problematic in the present study, which used the stems from existing collective narcissism items, as the framing of these items may have politically-salient themes (e.g., hierarchy) embedded within them. As alluded to in the introduction to this paper, this is not a problem that is limited to the measurement of collective narcissism, but may be symptomatic of some 
degree of bias in the social psychological measurement of politically-salient individual difference constructs (Reyna, 2018). As such, an interesting avenue for advancing crossspectrum research into political divisions might be to develop more ideologically-nonspecific measures of key constructs.

\section{Implications for the 'microaggression' concept}

These results are indicative of the ideological basis of microaggression perception, and support the critical comments of Elliott (2016) and Lilienfeld (2017) in arguing that the identification of so-called microaggressions may related to receiver perceptions than the malevolent intent of the 'perpetrator'. This study goes further than these reviews by providing data about the ideological nature of microaggression perception, and provides direct evidence against the standard demographic view.

That is, data collected in this study allowed for a direct comparison to be made between an interaction between participant gender and victim gender on the one hand, and participant ideology and victim gender on the other, in relation to gender-based microaggressions. In this exploratory analysis, there was no main effect of victim gender, and no interaction between this and participant gender in microaggression perception. This is evidence against the standard microaggression conceptualization, as subtle slights made against women were viewed in the same manner as those made against men (and female participants were not more susceptible to perceiving greater malevolence when slights were directed towards women, given their alleged minority position in society). In contrast, there was a significant interaction between participants' ideological orientation and the alleged victim's gender. Self-identifying liberals viewed 'microaggressions' against women as more malevolent than the same messages communicated about men, while self-identifying conservatives expressed the opposite microaggression perceptions. 
When adding this exploratory analysis to the main confirmatory hypothesis testing in this paper, a clear argument begins to emerge. That is, individuals infer malevolent intent across the ideological spectrum when 'victim groups' associated with their 'side' are perceived to be under attack. In short, 'microaggressions' may not represent a unique contribution to the empirical literature on intergroup relations (a point also made by Lilienfeld, 2017). Instead, this label may be a hyperbolic (in the priming of 'aggression') label that is reflective of a host of well-known psychological tendencies to shun or discredit those with whom we are ideologically opposed (e.g., Appiah, Knobloch-Westerwick, \& Alter, 2013; Branscombe \& Wann, 1994; van Prooijen, Krouwel, Boiten, \& Eendebak, 2015). Indeed, there are emerging arguments within political psychology that suggest some degree of political symmetry between those on the political left and right (e.g., Crawford, 2014; Frimer et al., 2017; Washburn \& Skitka, 2017).

By using a range of stimuli within an ecological framework (Kessler et al., 2017), this study was able to demonstrate the falsifiability of the traditional power-based (demographic) conceptualization of 'microaggressions', as advanced by Sue (2010). In doing so, the data reported here are indicative of the fact that 'microaggressions' can be subsumed into the existing literature on motivated social cognition, and support some recent concerns about the widespread adoption of policies designed to counter such interactions on the basis of this traditional conceptualization (e.g., Lilienfeld, 2017).

This re-interpretation (or subsuming) of the 'microaggression' concept has implications for the expanding policies related to 'unconscious bias training' and policies to 'improve diversity' in a range of occupational settings. It is clear that these policies are wellintentioned. However, their focus on women, ethnic and sexual minorities, and other ostensibly disadvantaged populations risks further polarization, while ignoring the many subtle insults that may be faced by people who are not members of these groups. This may 
especially be the case in settings whereby there is an over-representation of left-leaning administrators (e.g., universities, where such policies have been particularly welldocumented; see Noon, 2018), as the focus of such diversity initiatives are inevitably focused in one political direction in these contexts. Importantly, if diversity instructors present ideologically-motivated examples to politically-diverse audiences, it is little surprise that 'implicit bias training' typically does not lead to long-term improvements in diversity-related attitudes (Lai et al., 2016). That is, to those approaching the training from an alternative ideological position, the facilitators of these courses may be seen as pandering to mainstream concerns, rather than addressing perceived prejudice across the entirety of the ideological spectrum.

\section{Limitations and future directions}

Some critics may refute this reconstrual of the microaggression concept by drawing on Sue's (2010) initial definition of microaggressions. That is, an argument against the motivated cognition conclusion presented here could be based around the idea that majority group members cannot be microaggressed against due to their powerful position in society (relatedly, this is an argument against so-called 'reverse discrimination'; for a discussion, see Kalunta-Crumpton, 2017). However, this may be an arbitrary distinction to draw based on a potentially flawed conceptual framework, as reviewed in the introduction to this paper (e.g., microaggression perception can be viewed as an emotional reaction to identity-based outgroup malevolence, rather than a specific and empirically-measurable phenomena). Further, as identity politics take a firmer hold over social and political discussions, even traditional 'majority' identities become central aspects of people's lives. As such, perceived attacks based on such factors do appear to be subsumed under an identity-based conceptualization of microaggressions. 
One potential rebuttal of the design of the present study is related to the use of a single 'microaggression' scenario on which to obtain participants' perceptions. That is, the MAT asserts that microaggressions are low-level subtle messages that occur undetected on a regular basis in everyday life. However, this critique again points to a lack of internal consistency within the microaggression research program. For instance, The University of California - Santa Cruz (2010) list of microaggressions give concrete examples of specific incidents that allegedly represent microaggressive actions. Similarly, surveys of the prevalence of microaggressions in different demographic groups ask respondents to rate how often they perceive that they have been disrespected or treated rudely "more than a few times a year but less than monthly" (e.g., Torres, Driscoll, \& Burrow, 2010, p. 1089). As such, examining perceptions of individual examples that are temporally unlinked to each other does seem to be valid approach to studying judgements of alleged microaggressions.

Further, the examples used in the present study were based on contemporary cultural debates (Campbell \& Manning, 2018), and framed within the college context (consistent with mainstream discussions about microaggressive interactions). As such, ecological validity can also be said to be high in the present study. However, this could also be a drawback of the present investigation, as the findings are not necessarily generalizable to wider contexts. For example, women are now the dominant sex in a wide array of academic disciplines at undergraduate level (Lopez \& Gonzalez-Barrera, 2014), but are still under-represented in political and corporate contexts (Brown, 2017). As such, framing these scenarios in terms of the corporate environment may lead to exaggerated ideologically-driven (and perhaps demographically-driven) perceptions of microaggressions than those purely presented as taking place within the college context.

This study was set-up to examine ideologically-driven perceptions of alleged microaggressive behaviors. As such, other moderators of these perceptions were not 
measured here. Future studies might investigate the personality- and emotionally-based moderators of ideological microaggression perception. For example, negative emotionality (Watson \& Clark, 1984) and high neuroticism (particularly the aspect of volatility; DeYoung et al., 2007) may be interesting candidates for psychological moderators of microaggression perceptions. This would also be in line with Lilienfeld's (2017) critique of the microaggression concept.

\section{Conclusion}

In summary, the data presented here are suggestive of a motivated approach, across the ideological spectrum, in forming judgements about interactions that could be classified as 'microaggressions'. In doing so, these findings challenge the conventional power-based definitions of the microaggression concept. Instead, microaggression perception may merely be a manifestation of motivated social cognition linked to outgroup derogation under conditions of perceived ingroup threat. Addressing the potentially skewed nature of social discussions about 'perpetrator' and 'victim' groups could help to redress this balance and reduce automatic polarized responses to perceived malevolence across the ideological spectrum. 


\section{References}

Appiah, O., Knobloch-Westerwick, S., \& Alter, S. (2013). Ingroup favoritism and outgroup derogation: Effects of news valence, character race, and recipient race on selective news reading. Journal of Communication, 63, 517-534. doi: 10.1111/jcom.12032.

Balota, D. A. (2016). Speed reading: You can't always get what you want, but can you sometimes get what you need? Psychological Science in the Public Interest, 17, 1-3. doi: $10.1177 / 1529100615623268$.

Brandt, M. J., \& Spälti, A. K. (2018). Norms and explanations in social and political psychology. In J. T. Crawford and L. Jussim (Eds.). The politics of social psychology (pp. 26-43). New York, NY: Routledge.

Branscombe, N. R., \& Wann, D. L. (1994). Collective self-esteem consequences of outgroup derogation when a valued social identity is on trial. European Journal of Social Psychology, 24, 641-657. doi: 10.1002/ejsp.2420240603.

British Psychological Society. (2014). Code of human research ethics. Leicester: Author.

Brown, A. (2017). Despite gains, women remain underrepresented among U.S. political and business leaders. Retrieved from: http://www.pewresearch.org/fact$\operatorname{tank} / 2017 / 03 / 20 /$ despite-gains-women-remain-underrepresented-among-u-s-political-andbusiness-leaders/.

Campbell, B., \& Manning, J. (2018). The rise of victimhood culture: Microaggressions, safe spaces, and the new culture wars. Cham, Switzerland: Springer International Publishing.

Carney, D. R., Jost, J. T., Gosling, S. D., \& Potter, J. (2008). The secret lives of liberals and conservatives: Personality profiles, interaction styles, and the things they leave behind. Political Psychology, 29, 807-840. doi: 10.1111/j.1467-9221.2008.00668.x. 
Cichocka, A. (2016). Understanding the role of defensive and secure in-group positivity: The role of collective narcissism. European Review of Social Psychology, 27, 283-317. doi: 10.1080/10463283.2016.1252530.

Costa, P. T., \& McCrae, R. R. (1992). Revised NEO Personality Inventory (NEO-PI-R) and NEO Five-Factor Inventory (NEO-FFI) manual. Odessa, FL: Psychological Assessment Resources.

Crawford, J. T. (2014). Ideological symmetries and asymmetries in political intolerance and prejudice toward political activist groups. Journal of Experimental Social Psychology, 55, 284-298. doi: 10.1016/j.jesp.2014.08.002.

Crawford, J. T., Kay, S. A., \& Duke, K. E. (2015). Speaking out of both sides of their mouths: Biased political judgments within (and between) individuals. Social Psychological and Personality Science, 6, 422-430. doi: 10.1177/1948550614566858.

DeYoung, C. G., Quilty, L. C., \& Peterson, J. B. (2007). Between facets and domains: 10 aspects of the Big Five. Journal of Personality and Social Psychology, 93, 880-896. doi: 10.1037/0022-3514.93.5.880.

Elliott, I. A. (2016, June 8). Microaggression theory: Check thy privilege! Retrieved from https://ianaelliott.wordpress.com/2016/06/08/microaggression-theory-check-thy-privilege/.

Faul, F., Erdfelder, E., Buchner, A., \& Lang, A.-G. (2009). Statistical power analyses using G*Power 3.1: Tests for correlation and regression analyses. Behavior Research Methods, 41, 1149-1160. doi :10.3758/BRM.41.4.1149

Friedersdorf, C. (2015, September 11). The rise of victimhood culture. The Atlantic. Retrieved from http://www.theatlantic.com/politics/archive/2015/09/the-rise-ofvictimhood-culture/404794/. 
Frimer, J. A., Tell, C. E., \& Motyl, M. (2016). Sacralizing liberals and fair-minded conservatives: Ideological symmetry in the moral motives in the culture war. Analyses of Social Issues and Public Policy. Advance online publication. doi: 10.1111/asap.12127.

Frimer, J. A., Skitka, L. J., \& Motyl, M. (2017). Liberals and conservatives are similarly motivated to avoid exposure to one another's opinions. Journal of Experimental Social Psychology, 72, 1-12. doi: 10.1016/j.jesp.2017.04.003.

Goldberg, L. R. (1993). The structure of phenotypic personality traits. American Psychologist, 48, 26-34. doi:10.1037/0003-066x.48.1.26.

Golec de Zavala, A., \& Cichocka, A. (2012). Collective narcissism and anti-Semitism in Poland. Group Processes and Intergroup Relations, 15, 213-229. doi: $10.1177 / 1368430211420891$.

Golec de Zavala, A., Cichocka, A., \& Bilewicz, M. (2013). The paradox of in-group love: differentiating collective narcissism advances understanding of the relationship between in-group and out-group attitudes. Journal of Personality, 81, 16-28. doi: 10.1111/j.14676494.2012.00779.x.

Golec de Zavala, A., Cichocka, A., Eidelson, R., \& Jayawickreme, N. (2009). Collective narcissism and its social consequences. Journal of Personality and Social Psychology, 97, 1074-1096. doi: 10.1037/a0016904.

Golec de Zavala, A., Peker, M., Guerra, R., \& Baran, T. (2016). Collective narcissism predicts hypersensitivity to in-group insult and direct and indirect retaliatory intergroup hostility. European Journal of Psychology, 30, 532-551. doi: 10.1002/per.2067.

Graham, J., Nosek, B. A., \& Haudt, J. (2012). The moral stereotypes of liberals and conservatives: Exaggeration of differences across the political spectrum. Plos ONE, 7, 113. doi: 10.1371/journal.pone.0050092. 
Haidt, J. (2012). The righteous mind: Why good people are divided by politics and religion. London: Penguin.

Hayes, A. (2013). Introduction to mediation, moderation, and conditional process analysis: A regression-based approach. New York, NY: Guilford Press.

Ho, A. K., Sidanius, J., Kteily, N., Sheehy-Skeffington, J., Pratto, F., Henkel, K. E., Foels, R., \& Stewart, A. L. (2015). The nature of social dominance orientation: Theorizing and measuring preferences for intergroup inequality using the new $\mathrm{SDO}_{7}$ scale. Journal of Personality and Social Psychology, 109, 1003-1028. doi: 10.1037/pspi0000033.

Hodson, G., \& Dhont, K. (2015). The person-based nature of prejudice: Individual difference predictors of intergroup negativity. European Review of Social Psychology, 26, 1-42. doi: 10.1080/10463283.2015.1070018.

Jost, J. T. (2017). Ideological asymmetries and the essence of political psychology. Political Psychology, 38, 167-208. doi: 10.1111/pops.12407.

Jost, J. T., \& Amodio, D. M. (2012). Political ideology as motivated social cognition: Behavioral and neuroscientific evidence. Motivation and Emotion, 36, 55-64. doi: $10.1007 / \mathrm{s} 11031-011-9260-7$.

Kalunta-Crumpton, A. (2017). Is there no such thing as non-White racism? Comparative Sociology, 16, 656-684. doi: 10.1163/15691330-12341440.

Kessler, T., Proch, J., \& Elad-Strenger, J. (2017, June). Brunswik meets politics: Toward an ecological approach to political psychology. Paper presented at the International Society of Political Psychology Annual Conference, Edinburgh, UK.

Lai, C. K., Skinner, A. L., Cooley, E., Murrar, S., Brauer, M., Devos, T., Calanchini, J., Xiao, Y. J., Pedram, C., Marshburn, C. K., Simon, S., Blanchar, J. C., Joy-Gaba, J. A., Conway, J., Redford, L., Klein, R. A., Roussos, G., Schellhaas, F. M., Burns, M., McLean, M. C., Axt, J. R., Asgari, S., Schmidt, K., Rubinstein, R., Marini, M., Rubichi, S., Shin, J. E., \& 
Nosek, B. A. (2016). Reducing implicit racial preferences: II. Intervention effectiveness across time. Journal of Experimental Psychology: General, 145, 1001-1016. doi: 10.1037/xge0000179.

Lilienfeld, S. O. (2017). Microaggressions: Strong claims, inadequate evidence. Perspectives on Psychological Science, 12, 138-169. doi: 10.1177/1745691616659391.

Lopez, M. H., \& Gonzalez-Barrera, A. (2014). Women's college enrollment gains leave men behind. Retrieved from : http://www.pewresearch.org/fact-tank/2014/03/06/womenscollege-enrollment-gains-leave-men-behind/.

Murteira, C., Golec de Zavala, A., \& Waldzus, S. (2017, June). Collective narcissists under threat mimic outgroup anger more than in-group anger. Paper presented the International Society of Political Psychology Annual Conference, Edinburgh, UK.

Nadal, K. L. (2010). The racial and ethnic microaggressions scale (REMS): Construction, reliability, and validity. Journal of Counseling Psychology, 58, 470-480. doi: 10.1037/a0025193.

Noon, M. (2018). Pointless diversity training: Unconscious bias, new racism and agency. Work, Employment and Society, 32, 198-209. doi: 10.1177/0950017017719841.

Picower, B. (2013). Education should be free! Occupy the DOE!: Teacher activists involved in the Occupy Wall Street movement. Critical Studies in Education, 54, 44-56. doi: $10.1080 / 17508487.2013 .739569$.

Pinker, S. (2002). The blank slate: The modern denial of human nature. London: Penguin. Reyna, C. (2018). Scale creation, use, and misuse: How politics undermines measurement. In J. T. Crawford and L. Jussim (Eds.). The politics of social psychology (pp. 81-98). New York, NY: Routledge. 
Skitka, L. J., Hanson, B. E., \& Wisneski, D. C. (2017). Utopian hopes or dystopian fears? Exploring the motivational underpinnings of moralized political engagement. Personality and Social Psychology Bulletin, 43, 177-190. doi: 10.1177/0146167216678858.

Stevens, S. (2017). Campus speaker disinvitations: Recent trends (part 1 of 2). Retrieved from: http://heterodoxacademy.org/campus-speaker-disinvitations-recent-trends-part-1-of$2 /$.

Sue, D. W. (2010). Microaggressions in everyday life: Race, gender, and sexual orientation. Hoboken, NJ: Wiley.

Sue, D. W., Bucceri, J. M., Lin, A. I., Nadal, K. L., \& Torino, G. C. (2009). Racial microaggressions and the Asian American experience. Asian American Journal of Psychology, S, 88-101. doi:10.1037/1948-1985.S.1.88.

Sue, D. W., Capodilupo, C. M., \& Holder, A. B. (2008). Racial microaggressions in the life experience of Black Americans. Professional Psychology: Research and Practice, 39, 329-336. doi: 10.1037/0735-7028.39.3.329.

Talhelm, T., Haidt, J., Oishi, S., Zhang, X., Miao, F. F., \& Chen, S. (2015). Liberals think more analytically (more "WEIRD") than conservatives. Personality and Social Psychology Bulletin, 41, 250-267. doi: 10.1177/0146167214563672.

Torres, L., Driscoll, M. W., \& Burrow, A. L. (2010). Racial microaggressions and psychological functioning among high-achieving African-Americans: A mixed-methods approach. Journal of Social and Clinical Psychology, 29, 1074-1099. doi: 10.1521/jscp.2010.29.10.1074.

University of California - Santa Cruz. (2015). Tool: Recognizing microaggressions and the messages they send. Retrieved from: https://academicaffairs.ucsc.edu/events/documents/Microaggressions_Examples_Arial_20 14_11_12.pdf. 
van Prooijen, J.-W., Krouwel, A. P. M., Boiten, M., \& Eendebak, L. (2015). Fear among the extremes: How political ideology predicts negative emotions and outgroup derogation. Personality and Social Psychology Bulletin, 41, 485-497. doi: $10.1177 / 0146167215569706$.

Washburn, A. N., \& Skitka, L. J. (2017). Science denial across the political divide: Liberals and conservatives are similarly motivated to deny attitude-inconsistent science. Social Psychological and Personality Science. Advance online publication. doi: $10.1177 / 1948550617731500$.

Watkins, N. L., LaBarrie, T. L., \& Appio, L. M. (2010). Black undergraduates experience with perceived racial microaggressions in predominantly White colleges and universities. In D. W. Sue (Ed.), Microaggressions and marginality: Manifestation, dynamics, and impact (pp. 25-58). New York, NY: Wiley \& Sons.

Watson, D., \& Clark, L. A. (1984). Negative affectivity: The disposition to experience aversive emotional states. Psychological Bulletin, 96, 465-490. doi: 10.1037/00332909.96.3.465. 


\section{Appendix - Vignettes Used in the Study}

\section{Left-wing racial microaggression vignette}

Charles Richardson, a White professor of political psychology, was giving a speech to a class of seniors about racial differences in the workplace. He made several suggestions about how Whites and Blacks appear to have different cultural influences, and that this may explain the differences in pay between Whites (who typically are paid more) and Blacks (whose average income is typically less).

On hearing this, a Black student named Andre raised his hand. When called upon, the student spoke in a frustrated manner, noting that the history of race relations was as such that it meant that action was needed to address the lack of equality between Whites and Blacks. The student seemed to challenge the professor by stressing the contributions that African Americans had made in the business world when they had been given the opportunity to do so.

The professor responded, “Andre, you need to calm down. We are studying American society in this course and we will eventually address how it has influenced and been adapted or informed by a range of groups. This is not the place for policy agendas."

Rather than defusing the situation, however, Professor Richardson sensed that his response had raised the level of tension among several students of color. Another Black student then stated, "Perhaps we are looking at this issue from different perspectives or worldviews. Just as language affects how we define problems, maybe we all need to evaluate our assumptions and beliefs. Maybe there are aspects of psychology that apply across all populations that you haven't covered here."

Professor Richardson looked surprised at this student's approach. “Actually, Justin, that's right. It is refreshing to hear such a measured response". To the professor's surprise, though, Justin and several other students of color seemed offended and insulted by the praise. 


\section{Left-wing gender microaggression vignette}

Charles Richardson, a male professor of political psychology, was giving a speech to a class of seniors about gender-based differences in the workplace. He made several suggestions about how men and women appear to make different life decisions, and that this may explain the differences in pay between men (who typically are paid more) and women (whose average income is typically less).

On hearing this, a female student named Amber raised her hand. When called upon, the student spoke in a frustrated manner, noting that the socialisation of boys and girls, and the patriarchal nature of society, was as such that it meant that action was needed to address the lack of equality between the genders. The student seemed to challenge the professor by stressing the contributions that women had made in the business world when they had been given the opportunity to do so.

The professor responded, "Amber, you need to calm down. We are studying American society in this course and we will eventually address how it has influenced and been adapted or informed by a range of groups. This is not the place for policy agendas."

Rather than defusing the situation, however, Professor Richardson sensed that his response had raised the level of tension among several female students. Another of them then stated, "Perhaps we are looking at this issue from different perspectives or worldviews. Just as language affects how we define problems, maybe we all need to evaluate our assumptions and beliefs. Maybe there are aspects of psychology that apply across all populations that you haven't covered here."

Professor Richardson looked surprised at this student's approach. “Actually, Jennifer, that's right. It is refreshing to hear such a measured response". To the professor's surprise, though, Jennifer and several other female students seemed offended and insulted by the praise. 


\section{Left-wing political microaggression vignette}

Charles Richardson, a Republican-voting professor of political psychology, was giving a speech to a class of seniors about his research. He made several suggestions about there are many more liberals than conservatives on campus, and that this risks shutting down constructive debate and endangers students' chances when they graduate.

On hearing this, a liberal student named Aaron raised his hand. When called upon, the student spoke in a frustrated manner, noting that the liberals are well-placed to present a range of political viewpoints, and that action was needed to ensure that the liberal voice was not lost. The student seemed to challenge the professor by stressing the contributions that those on the political left had made to the lives and achievements of a range of students when they had been given the opportunity to do so.

The professor responded, “Aaron, you need to calm down. We are studying American society in this class and we will eventually address how it has influenced and been adapted or informed by a range of groups. This is not the place for policy agendas."

Rather than defusing the situation, however, Professor Richardson sensed that his response had raised the level of tension among several liberal students. Another of them then stated, "Perhaps we are looking at this issue from different perspectives or worldviews. Just as language affects how we define problems, maybe we all need to evaluate our assumptions and beliefs. Maybe there are aspects of psychology that apply across all populations that you haven't covered here."

Professor Richardson looked surprised at this student's approach. “Actually, John, that's right. It is refreshing to hear such a measured response". To the professor's surprise, though, John and several other female students seemed offended and insulted by the praise. 


\section{Right-wing racial microaggression vignette}

Erik Ong, an Asian professor of political psychology, was giving a speech to a class of seniors about racial differences in educational attainment. He made several suggestions about how Whites and Asians appear to have different cultural influences, and that this may explain the differences in grades between Whites (who typically do worse in school) and Asians (whose average grades are typically higher).

On hearing this, a White student named Chris raised his hand. When called upon, the student spoke in a frustrated manner, noting that recent trends in promoting diversity were such that it meant that action was needed to address the lack of equality between Whites and Asians. The student seemed to challenge the professor by stressing the positive achievements of White students in the class when they had been given some support.

The professor responded, "Chris, you need to calm down. We are studying American society in this course and we will eventually address how it has influenced and been adapted or informed by a range of groups. This is not the place for policy agendas."

Rather than defusing the situation, however, Professor Ong sensed that his response had raised the level of tension among several White students. Another White student then stated, "Perhaps we are looking at this issue from different perspectives or worldviews. Just as language affects how we define problems, maybe we all need to evaluate our assumptions and beliefs. Maybe there are aspects of psychology that apply across all populations that you haven't covered here."

Professor Ong looked surprised at this student's approach. “Actually, Justin, that's right. It is refreshing to hear such a measured response". To the professor's surprise, though, Justin and several other White students seemed offended and insulted by the praise. 


\section{Right-wing gender microaggression vignette}

Sarah Henderson, a female professor of political psychology, was giving a speech to a class of seniors about gender-based differences in educational attainment. She made several suggestions about how males and female students appear to have different cultural influences, and that this may explain the differences in grades between males (who typically do worse in school) and females (whose average grades are typically higher).

On hearing this, a male student named Chris raised his hand. When called upon, the student spoke in a frustrated manner, noting that recent trends in promoting diversity were such that it meant that action was needed to address the lack of equality between males and females. The student seemed to challenge the professor by stressing the positive achievements of male students in the class when they had been given some support.

The professor responded, "Chris, you need to calm down. We are studying American society in this course and we will eventually address how it has influenced and been adapted or informed by a range of groups. This is not the place for policy agendas."

Rather than defusing the situation, however, Professor Henderson sensed that her response had raised the level of tension among several male students. Another male student then stated, "Perhaps we are looking at this issue from different perspectives or worldviews. Just as language affects how we define problems, maybe we all need to evaluate our assumptions and beliefs. Maybe there are aspects of psychology that apply across all populations that you haven't covered here."

Professor Henderson looked surprised at this student's approach. "Actually, Justin, that's right. It is refreshing to hear such a measured response". To the professor's surprise, though, Justin and several other male students seemed offended and insulted by the praise. 


\section{Right-wing political microaggression vignette}

Charles Richardson, a Democrat-voting professor of political psychology, was giving a speech to a class of seniors about his research. He made several suggestions about there are many more conservatives than liberals on campus, and that this risks shutting down constructive debate and endangers students' chances when they graduate.

On hearing this, a conservative student named Aaron raised his hand. When called upon, the student spoke in a frustrated manner, noting that the conservatives are well-placed to present a range of political viewpoints, and that action was needed to ensure that the conservative voice was not lost. The student seemed to challenge the professor by stressing the contributions that those on the political right had made to the lives and achievements of a range of students when they had been given the opportunity to do so.

The professor responded, "Aaron, you need to calm down. We are studying American society in this class and we will eventually address how it has influenced and been adapted or informed by a range of groups. This is not the place for policy agendas."

Rather than defusing the situation, however, Professor Richardson sensed that his response had raised the level of tension among several conservative students. Another of them then stated, "Perhaps we are looking at this issue from different perspectives or worldviews. Just as language affects how we define problems, maybe we all need to evaluate our assumptions and beliefs. Maybe there are aspects of psychology that apply across all populations that you haven't covered here."

Professor Richardson looked surprised at this student's approach. “Actually, John, that's right. It is refreshing to hear such a measured response". To the professor's surprise, though, John and several other female students seemed offended and insulted by the praise. 